\title{
Unconscious Biases: Racial Microaggressions in American Indian Health Care
}

\author{
Melissa L. Walls, PhD, John Gonzalez, PhD, Tanya Gladney, PhD, and \\ Emily Onello, $M D$
}

Purpose: This article reports on the prevalence and correlates of microaggressive experiences in health care settings reported by American Indian (AI) adults with type 2 diabetes mellitus (T2DM).

Methods: This community-based participatory research project includes two AI reservation communities. Data were collected via in-person article-and-pencil survey interviews with $218 \mathrm{AI}$ adults diagnosed with T2DM.

Results: Greater than one third of the sample reported experiencing a microaggression in interactions with their health providers. Reports of microaggressions were correlated with self-reported history of heart attack, worse depressive symptoms, and prior-year hospitalization. Depressive symptom ratings seemed to account for some of the association between microaggressions and hospitalization (but not history of heart attack) in multivariate models.

Conclusions: Microaggressive experiences undermine the ideals of patient-centered care and in this study were correlated with worse mental and physical health reports for AIs living with a chronic disease. Providers should be cognizant of these subtle, often unconscious forms of discrimination. ( $\mathrm{J}$ Am Board Fam Med 2015;28:231-239.)

Keywords: Cross-Cultural Care; Patient-Centered Care; Populations, Underserved

Despite countless calls to action to address health equity issues, there remain persistent and in some cases widening gaps in health status between the most advantaged and disadvantaged members of

This article was externally peer reviewed.

Submitted 7 July 2014; revised 10 October 2014; accepted 20 October 2014.

From the Department of Biobehavioral Health and Population Sciences, University of Minnesota Medical School-Duluth, Duluth, MN (MLW); Department of Psychology, Bemidji State University, Bemidji, MN (JG); Department of Sociology and Criminal Justice, University of St. Thomas, St. Paul, MN (TG); Department of Family Medicine/Community Health, University of Minnesota Medical School-Duluth, Duluth, MN (EO).

Funding: Research reported in this paper was supported by the National Institute of Mental Health under Award Number MH085852 (M.L.W., Principal Investigator).

Conflict of interest: none declared.

Disclaimer:The content is solely the responsibility of the authors and does not necessarily represent the official views of the National Institutes of Health.

Although "Chippewa" is a corruption of "Ojibwe," "Chippewa" has been used by the federal government in all major treaty negotiations, government-to-government negotiations, and legal cases involving Ojibwe bands. Although many members of this group prefer the term "Anishinabe" or "Ojibwe," the term "Chippewa" is currently incorporated into a number of legal tribal and band names. society. One striking illustration of racial/ethnic health disparities is found among American Indian/Alaska Native (AIAN) communities across the United States, who suffer among the highest rates of poor physical and mental health including type 2 diabetes mellitus (T2DM), cardiovascular problems, suicide, and mental distress. ${ }^{1}$ Numerous factors are implicated as key contributors to health disparities in general, including social exclusion and marginalization, poverty, stress, and other critical social determinants of health. ${ }^{2,3}$ In the clinical arena, evidence from the National Health Care Quality and Disparities Report reveals that AIANs received worse health care than whites on approximately one third of quality care indicators. ${ }^{4}$ Compared with all other racial/ethnic groups included in the report, AIANs reported the smallest proportion of improvement across these quality measures.

Corresponding author: Melissa L.Walls, $\mathrm{PhD}$, Department of Biobehavioral Health and Population Sciences, University of Minnesota Medical School-Duluth, 1035 University Drive, 235 S Med, Duluth, MN 55812 (E-mail: mlwalls@d.umn.edu). 
One response to such trends has been renewed focus on culturally safe (sometimes referred to as culturally "competent"), patient-centered medical care and increased awareness of the harmful health impacts of racism and discriminatory treatment for patients from diverse groups. Less understood are the elusive yet damaging effects of microaggressive experiences. Microaggressions describe the frequent, subtle (often unconscious) indignities expressed in relation to one's gender, race, sexual orientation, or otherwise-marginalized social position. ${ }^{5}$ The potential impact of microaggressions in clinical encounters is notable given the providerpatient relationship and inherent power differential wherein authority and prestige favors the clinician. When a health care provider commits a microaggression, the exchange may undermine attempted provision of care, trust may be broken, and the visit becomes a source of patient stress. Microaggressions are possible in any intercultural exchange and are liable to be enacted by all of us, including the most caring, sensitive providers. Thus, there is great impetus for critical self reflection and broadened understanding of microaggressions to achieve high-quality, culturally safe care.

Although a growing literature explores the consequences of health care-related discrimination in multiple forms, investigation of microaggressive health care experiences specifically has received almost no empirical attention. In this study, we examine the prevalence of microaggressive experiences in health care settings and their association with health outcomes and behaviors for a sample of AI adults living with T2DM.

\section{Literature Review}

The relationship between stress and health is well established. ${ }^{6-12}$ Psychosocial stress can adversely affect health in two major ways: directly, through neurochemical pathways; and indirectly, by promoting unhealthy behaviors. An intimate understanding of the sociocultural contexts of stress is key to adequately conceptualizing and measuring the "stress universe,"13 a term used to describe exposure to variable forms of stressors. Interwoven within this context for people of color including AIs are experiences of discrimination acting as powerful stressors due to their unpredictable and uncontrollable nature. ${ }^{14}$ Only within the last 15 or so years has the link between discrimination and health been seriously considered as contributing to health dispari- ties, whether occurring in everyday situations ${ }^{15-17}$ or when accessing health care services. ${ }^{18-20}$ For example, a review by Pascoe and Richman ${ }^{21}$ found that perceived discrimination is a significant predictor of disparities in hypertension, cardiovascular disease, diabetes, and respiratory conditions for racial minorities.

Numerous state, federal, and international reports reveal significant levels of racial discrimination by health care providers and within health systems and cite these factors as key mechanisms of health inequities. ${ }^{18,22-24}$ Members of racial minority groups are known to experience significantly more perceived discrimination from their providers than white patients, and provider discrimination predicts poorer health and less health care utilization. ${ }^{20}$ Health care professionals' unconscious biases toward racial ethnic minorities are also prevalent and negatively affect clinical relationships, patient satisfaction, quality of care, and communication style, ${ }^{22,25,26}$ thus contributing to worse health. A relatively recent framework for understanding these less overt biases is referred to as microaggressions. ${ }^{5,27}$

Microaggressions are commonly occurring indignities, slights, or insults that send a message of derogatory or negative status to members of marginalized groups. ${ }^{27}$ Microaggressions take on many forms. In a clinical relationship a provider may, for example, minimize racial/cultural issues; subtly communicate stereotypic assumptions; or overidentify with the patient's cultural background, at times due to assumed similarities with oppressive experiences. ${ }^{28}$ Attempts to call attention to such events may elicit additional microaggressive responses (eg, "you are being oversensitive," or, “you are pulling the 'race card'."). Because microaggressions are frequently "invisible" and unconscious, many are unlikely to examine their own role and impact as a microaggressor. ${ }^{5}$

To fully appreciate the potential effects of microaggressive stressors, each should be considered not as an isolated event, but as an instance within a broader pattern of oppression and discrimination. With regard to AI experiences, Sue asserts, "Microaggressions are linked to a wider sociopolitical context of oppression and injustice (historic trauma)... . For American Indians, their everyday lives are filled with reminders that their lands were unfairly seized from them, that they were forced onto reservations, and that physical and cultural 
genocide were visited on them." ${ }^{5}$ Thus, one single microaggressive experience might in and itself be stressful, and may also bring forth reminders of traumatic historic and ongoing oppression and mistreatment.

Among myriad health disparities endured by AI communities is the fact that AIs are more than twice as likely to have T2DM than non-Hispanic Whites. ${ }^{29}$ This disparity persists even after controlling for age, gender, other risk factors, and lifestyle characteristics. ${ }^{30}$ Given that diabetes care recommendations include regular follow-up with primary care providers to monitor disease management, engage in patient education, and track glycated hemoglobin (A1C) levels, ${ }^{31}$ T2DM prognosis is particularly prone to consequence if the patient/provider relationship is damaged by microaggressive encounters. For instance, research in the area of racial discrimination in health care systems (but not microaggressions specifically) established a link between health care discrimination and higher A1C levels among diabetic patients. ${ }^{32}$ Others have shown health care discrimination to be associated with increased diabetes-related complications and worse diabetes care. $^{33}$

In sum, discrimination and possibly microaggressions in health settings, particularly those enacted by health care providers, may contribute to worse health, decreased service utilization, and reduced treatment compliance. AIs endure disproportionate rates of numerous chronic diseases including T2DM, which requires frequent formal service utilization for disease monitoring and management. As such, AI communities may offer great insight into the ways in which microaggressions affects health behaviors and outcomes.

\section{Methods}

The Mino Giizhigad (A Good Day) Study is a community-based participatory research project with the Lac Courte Oreilles and Bois Forte Bands of Chippewa ${ }^{1}$ and the University of Minnesota. Both tribal communities wish to be named in public dissemination of research findings. The central purpose of the study was to describe the impact of mental health on diabetes-related outcomes among Ojibwe adults with T2DM. Tribal government support was obtained before applying for project funding. The project began with community feasts and forums to discuss the study goals, obtain com- munity feedback, and the establishment of Community Research Councils (CRCs). CRCs and University team members were active participants in the entire research process, including measurement adaptation and data collection and analysis. The University of Minnesota Institutional Review Board (IRB) and Indian Health Services National IRB reviewed and approved study methodologies.

Each community is home to its own tribal health clinic, and each employs one diabetes nurse educator. Both sites offer glucose testing and monitoring equipment, basic nutrition and exercise education, and coordinate community outreach initiatives including school-based healthy living programming. Participants for the current study were randomly selected from each reservation's health clinic records. Inclusion criteria were: patients 18 years or older, T2DM diagnosis, and self identified as AI. Our goal was to invite 300 patients (150 per site) to achieve a final sample size with adequate statistical power for planned multivariate analyses. Clinic partners used probability sampling to generate a random sample of 150 patients from their lists. Selected patients were mailed a welcome letter, brochure, and contact card with mail and phone-in options to decline participation. Because of budget limitations, the project design was limited to self report survey data. Trained community interviewers contacted nondeclining recruits to schedule the survey interviews. Participants were given a pound of locally cultivated wild rice and a $\$ 30$ cash incentive. Article-and-pencil interviewer administered surveys were completed in participants' location of choice, often in private spaces within homes. The time to complete each survey ranged between approximately $1.5-3$ hours.

Identifying information linked to surveys was removed and replaced with an identification number by on-site project coordinators before sending to the university. Survey data were entered and verified in electronic format by University research assistants. Of an initial eligible sample of 289 individuals ( 11 patients were ineligible because they did not have diabetes and/or were not AI), 218 participants completed surveys for a final study response rate of $75.4 \%$.

\section{Measures}

The University and community-based research team collaboratively reviewed, generated, and/or adapted all survey measures. Our central indepen- 
dent variable for this manuscript, Microaggressions, includes participants' indication of having ever experienced six ethnicity-related microaggressions from health care providers. Questions were adapted from the Racial Microaggressions in Counseling Scale ${ }^{28}$. Summed yes/no responses to the six items were used to compute an index of microaggressions in health care ranging from $0-6$ (Cronbach's $\alpha=0.85$ ).

We assessed associations between microaggressions and three health/behavioral health outcomes. Depressive symptoms are measured by scored responses $(0=$ not at all, $1=$ several days, $2=$ more than half the days, $3=$ almost every day) to nine items (PHQ- $9^{35}$ ) assessing symptoms of depression experienced in the 2 weeks before survey participation. We used a summed continuous score of this variable ranging in value from $0-27$. Heart attack is indicated by participant reports of having ever been told by a provider that they had experienced a heart attack. Past-year hospitalizations are measured by responses to a question asking participants how often had been a patient in a hospital overnight during the 12 months before their interview. To adjust for skewness, we truncated the hospital variable values to range from $0-2$.

Several control variables were also included. Gender is coded $0=$ male, $1=$ female. Although all participants in this study sought medical care at clinics located on reservation, some lived off reservation lands. We controlled for this with a dummy variable where $0=$ off reservation and $1=$ on reservation. Per capita household income was measured by asking respondents to indicate their overall household income within $\$ 10,000$ ranges. The final measure included the midpoints of these ranges divided by the number of people living within households. We also controlled for the number of years the participant had diabetes, the clinic site from which the patient was recruited (location $=0$ or 1 ), and self-reported age in years.

\section{Results}

Descriptive statistics for study variables are displayed in Table 1. The mean age of participants was 56.5 years and slightly over half of the sample was female. Average duration since T2DM diagnosis was approximately 15 years. Exactly $20 \%$ of the sample reported being hospitalized within the year before their interview date (the mean value of the continuous hospital-
Table 1. Descriptive Statistics for Self-Reported Survey Data from American Indian Patients with Type 2

\section{Diabetes}

\begin{tabular}{lcc}
\hline Variable & Mean or \% & SD \\
\hline Age & 56.5 & 13.7 \\
Gender (Female $=1)$ & $56 \%$ & - \\
On/Off Reservation (On = 1) & $78 \%$ & - \\
Years with Diabetes & 14.7 & 12.2 \\
Per capita household income (thousands) & 10.33 & 9.4 \\
Microaggressive experiences & 1.1 & 1.9 \\
Depressive symptoms & 4.54 & 5.5 \\
Past-year hospitalizations & $20 \%$ & - \\
History heart attack & $14 \%$ & - \\
\hline
\end{tabular}

SD, standard deviation.

ization variable used in analysis $=0.27$ ). The mean value of microaggressions $=1.1$, indicating that on average, respondents reported a little more than 1 microaggression experienced in health care settings.

Table 2 provides Pearson's $r$ correlation coefficients to illustrate bivariate relationships among all study variables. The microaggressions index was significantly and positively associated with self-reported heart attack history, past-year hospitalization, and depressive symptoms. None of the control variables were significantly associated with reported health care microaggressions in these bivariate correlations. Age was negatively associated with reports of depressive symptoms and positively related to history of heart attack.

Table 3 provides a breakdown of self-reported microaggressions experienced in health care settings. The most frequently reported microaggression related to stereotypes: "my health care provider sometimes seemed to have stereotypes about my cultural group, even if he or she did not express them directly." Endorsements ranged from 16$21.8 \%$ for the individual items. We also calculated a count of the prevalence of reporting any of the experiences and found that $36 \%$ of the sample experienced a microaggressive encounter in health care environments.

Regression results are presented in Table 4 with ordinary least squares regression for the continuous outcomes and logistic regression for the binary outcome, heart attack. The six control variables (age, gender, on/off reservation, clinic location, years living with diabetes, and per capita household income) and the microaggression variable were all regressed on each health/behavioral health out- 
Table 2. Bivariate Correlations (Pearson's r) Among Study Variables for American Indian Adults Living with Type 2 Diabetes

\begin{tabular}{|c|c|c|c|c|c|c|c|c|c|c|}
\hline \multirow[b]{2}{*}{ Variable } & \multicolumn{10}{|c|}{ Bivariate Correlations (Pearson's r) } \\
\hline & 1 & 2 & 3 & 4 & 5 & 6 & 7 & 8 & 9 & 10 \\
\hline 1. Age & 1 & & & & & & & & & \\
\hline 2. Gender $($ Female $=1)$ & $0.12^{*}$ & 1 & & & & & & & & \\
\hline 3. On/off reservation $(\mathrm{On}=1)$ & 0.001 & 0.04 & 1 & & & & & & & \\
\hline 4. Location & 0.05 & 0.00 & $0.30^{\dagger}$ & 1 & & & & & & \\
\hline 5. Years with diabetes & $0.33^{\dagger}$ & 0.09 & $0.14^{\S}$ & -0.002 & 1 & & & & & \\
\hline 6. Per capita household income (thousands) & 0.08 & 0.004 & $-0.19^{\ddagger}$ & -0.05 & 0.03 & 1 & & & & \\
\hline 7. Microaggressive experiences & -0.06 & -0.06 & -0.02 & -0.06 & 0.07 & -0.003 & 1 & & & \\
\hline 8. Depressive symptoms & $-0.21^{\ddagger}$ & 0.08 & -0.07 & -0.07 & -0.03 & $-0.16^{\S}$ & $0.22^{\ddagger}$ & 1 & & \\
\hline 9. Past-year hospitalizations & -0.03 & 0.01 & -0.10 & $-0.22^{\ddagger}$ & 0.01 & -0.03 & $0.16^{\S}$ & $0.23^{\ddagger}$ & 1 & \\
\hline 10. Heart attack & $0.25^{\dagger}$ & 0.01 & 0.03 & -0.09 & 0.08 & -0.06 & $0.17^{\S}$ & 0.09 & $0.14^{\S}$ & 1 \\
\hline
\end{tabular}

${ }^{*} P<.10$

${ }^{\dagger} P<.001$.

${ }^{\ddagger} P<.01$.

${ }^{\circledR} P<.05$.

come. After inclusion of control variables (Model 1, Table 4), microaggressive experiences were significantly and positively associated with depressive symptoms $(\beta=0.19, P<.01)$, past-year hospitalizations $(\beta=0.15, P<.05)$, and history of heart attack $(\mathrm{OR}=1.30, P<.05)$. Age was negatively associated with depressive symptoms and positively associated with heart attack history. Participant location was significantly associated with heart attack and hospitalizations, with those seeking treatment at community two more likely to report each of these issues.

To control for the possibility that those experiencing depressive symptoms may view provider

Table 3. American Indian Patient's Self-Reported Experiences with Microaggressions in Healthcare Settings

\begin{tabular}{lc}
\hline My healthcare provider... & $\%$ Yes \\
\hline $\begin{array}{l}\text { Avoided discussing or addressing cultural issues } \\
\text { Sometimes was insensitive about my cultural }\end{array}$ & 17.1 \\
$\quad \begin{array}{l}\text { group when trying to understand or treat my } \\
\text { issues }\end{array}$ & 17.3 \\
$\begin{array}{l}\text { Seemed to deny having any cultural biases or } \\
\text { stereotypes }\end{array}$ & 18.0 \\
$\begin{array}{l}\text { At times seemed to over-identify with my } \\
\text { experiences related to my race or culture }\end{array}$ & 16.0 \\
At times seemed to have stereotypes about my \\
$\quad \begin{array}{l}\text { cultural group, even if he or she did not } \\
\text { express them directly }\end{array}$
\end{tabular}

treatment more negatively than those are not, we included depressive symptoms as independent variables in Model 2 (Table 4) for the two clinical outcomes. We also calculated an interaction term between depressive symptoms and microaggressive experiences given their positive, significant association. We first review results when 'heart attack' is the dependent variable. As shown, after accounting for the control variables and microaggressions, patients reporting depressive symptoms were more likely to also report a history of heart attack. The inclusion of depressive symptoms in Model 2 slightly reduces the strength of the association between microaggressions and self-reported heart attack $(\mathrm{OR}=1.32$ in Model $1 ; \mathrm{OR}=1.28$ in Model $2)$, though the association remained statistically significant. The interaction term for depressive symptoms by microaggressions was not significant in this model (not shown).

Turning to the Hospitalization model, the association between microaggressions and pastyear hospitalization was no longer significant after inclusion of depressive symptoms. The interaction term for depressive symptoms by microaggressions was significant and is plotted Figure 1. The predicted coefficient for the dependent variable (past-year hospitalization) is diplayed on the y-axis. The illustration in Figure 1 reveals that patients reporting more microaggressions and more depressive symptoms were most likely to also report past-year hospitaliza- 


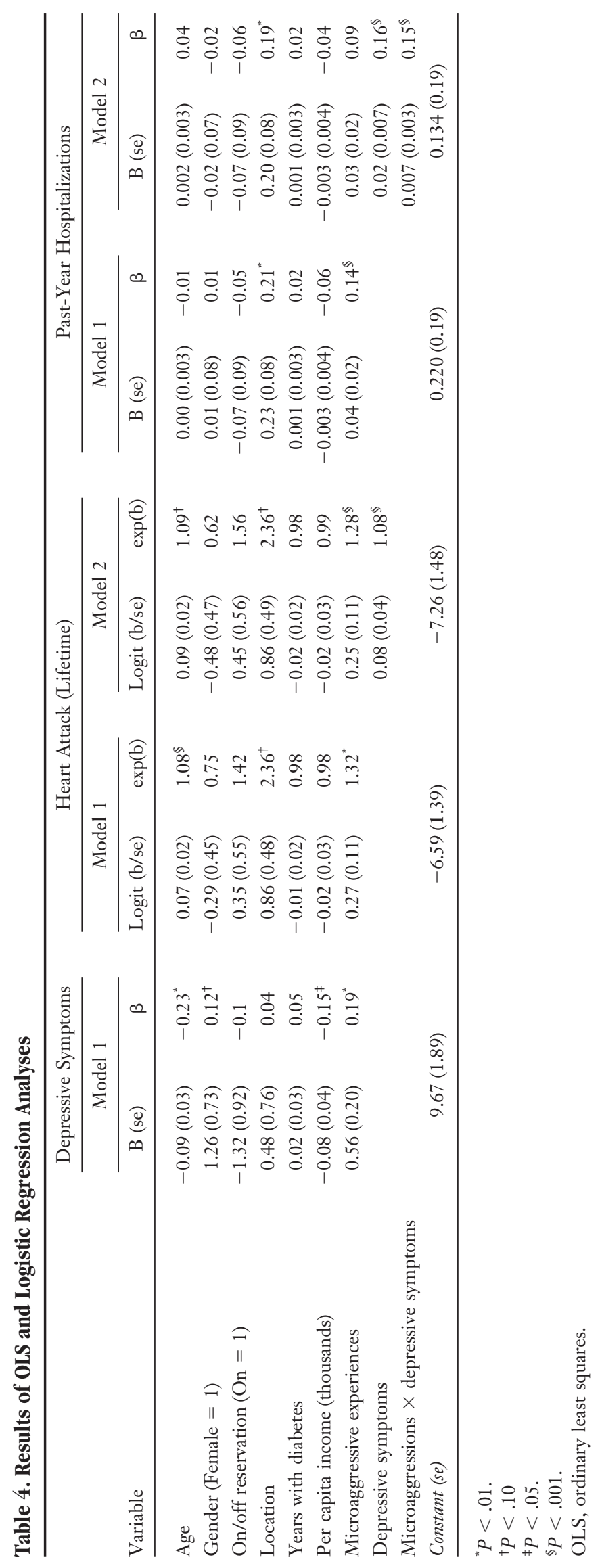


tion. Furthermore, hospitalization reports varied substantially by depressive symptom ratings for those higher on the microaggression scale. Depressive symptoms had less of an effect on hospitalizations among those reporting fewer microaggressions as shown in the bottom, diamondshaped labeled line of Figure 1.

\section{Discussion}

These data document associations between microaggressions experienced in health care settings and reports of worse physical, mental, and behavioral health for a sample of AI adults living with T2DM. Roughly $36 \%$ of participants reported having experienced microaggressions by their health care provider(s). Put another way, greater than one in three patients in this study reported a health care encounter in which a provider's words or behaviors (consciously or unconsciously) delivered a microaggressive message. After accounting for a number of control factors in multivariate models, these microaggressive experiences were associated with reports of hospitalization, history of heart attack, and depressive symptoms. Thus, we documented statistically significant cross-sectional associations between microaggressions in health care settings and worse mental and physical health outcomes.

We also examined the possible confounding and/or interactive effects of depressive symptoms on reports of microaggressions for the clinical outcome variables (heart attack and past-year hospitalizations, Model 2, Table 4). The association between microaggressive encounters and history of heart attack persisted even after accounting for depression levels. Alternatively, the association between microaggressions and hospitalization dropped from statistical significance when we included depressive symptoms in the model. It may be that the stressful nature of micro-

\section{Figure 1. Past year hospitalizations by depressive symptoms and microaggressive encounters.}

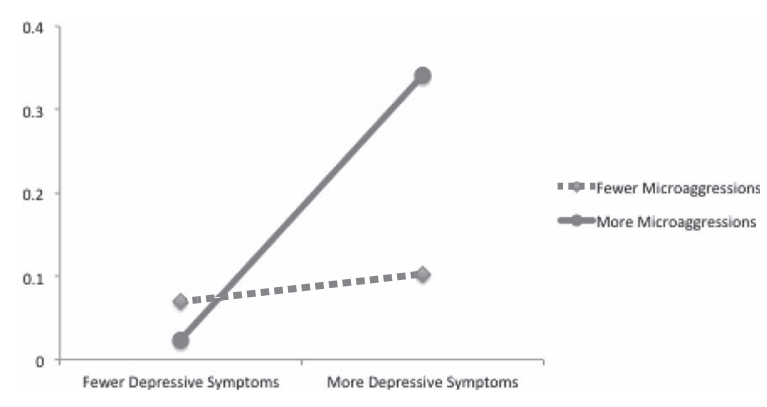

aggressions is more impactful on conditions like cardiovascular disease for which stress is an etiologic risk factor. Our investigation of interactive effects of depressive symptoms and microaggressions was significant in the Hospitalization model only. Specifically, we found that participants with higher scores on both the microaggression and depressive symptoms scales were most likely report past-year hospitalization (Figure 1). Furthermore, depressive symptom status seems to have the strongest effect on hospitalization for those participants who also reported higher instances of microaggressive experiences. One speculation for this trend is that factors that may be protective against depressive symptoms (eg, strong cultural identity, social support, spirituality, etc.) may also serve to offset the stressful effects of microaggressions. In the absence of those protective effects, patients may be simultaneously and differentially more vulnerable to the health consequences of both depressive symptoms and microaggressions, which could impact helpseeking behaviors such as scheduling and attending regular physician or clinic appointments. This could in turn result the worsening of health conditions that increase risk of hospitalization.

This research is a clear contribution given the central focus of previously published studies on mental health alone ${ }^{14,19}$ and documented relationships between discrimination and poor mental but not physical health. ${ }^{36}$ For patients living with a chronic disease such as T2DM, the implications of our findings are worrisome. Microaggressive encounters may be undermining the patient/provider relationship, which could contribute to disease complications and comorbidities. These results should, however, be interpreted with appropriate caution and impetus for further research. The cross-sectional data limit us from establishing temporal ordering of microaggressive experiences and health outcomes. We do not know whether microaggressions are contributing to worse outcomes as we theorize, or whether worse health leads to more health care experiences and potential to experience microaggressive exchanges with providers. The survey data are also subject to self-report bias, including potential bias in our outcome/clinical variables, which were not triangulated by medical chart data. In addition, our participatory research approach involved collaboration with two tribal clinics with potentially more AI staff and/or medical providers than found off reservations. We are not sure wher- 
her the microaggressions reported were more common at on-reservation facilities, or, if they occurred mainly in less frequent visits to off-reservation medical centers.

Future research should explore variability in microaggressive experiences in on/off-reservation settings to determine the full potential effect of these experiences for health behaviors and outcomes. Additional investigations should also clarify temporal ordering of microaggressions and adverse health (including physiologic assessments of health such as glycated hemoglobin [HbA1c] among T2 Days patients) via longitudinal designs. We also recommend qualitative investigation of microaggressions in health settings across diverse groups including AIs, which would yield deeper insights and understanding on the nature, reaction to, and personal impact of microaggressive encounters.

\section{Conclusion}

The concept of patient-centered care (PCC) has witnessed resurgent popularity in recent years as one potential response to evidence that negative patient/provider exchanges adversely impact patient health. Although definitions of PCC have evolved over the decades, a consistent theme promotes understanding of health and illness "through the patients eyes." 37 Microaggressions thus undermine PCC and deserve attention in the national conversation on patient-centered outcomes. PCC enacted impacts patient/provide communication in part through increased provider awareness of unconscious biases, sociocultural issues, and negotiation of diverse communication styles, all built on a foundation of respect and partnership. ${ }^{38}$ Understanding the changing face of racism to include the nuanced, often-unintended yet oppressive nature of microaggressions is a critical step in this regard.

Although cultural competency training is widespread throughout medicine, numerous authors remind us to be critical of the term competency, how it is perceived, and ultimately how it is employed. When too much focus rests on "memorizing" racial/ethnic differences and practices, cultural competency becomes stigmatizing and stereotypical to specific groups, ${ }^{39}$ possibly promoting microaggressive communication. Alternative approaches include cultural humility ${ }^{40}$ and cultural safety. ${ }^{41,42}$ These perspectives are similar to PCC in that patient care is seen as a dynamic, ongoing pro- cess $^{40}$ whereby physicians might: “....empathize with the lived experience of the patient's illness, and try to understand the illness as the patient understands, feels, perceives and respond to it." ${ }^{\text {39 }}$ The social power differential inherent to physician/patient relationships underscores the onus on clinicians to understand potential for and consequences of microaggressive encounters, and ultimately create a culturally safe health care environment for all.

The Mino Giizhigad Team includes Community Research Council members: Doris Isham, Julie Yaekel-Black Elk, Tracy Martin, Sidnee Kellar, Robert Miller, Geraldine Whiteman, Peggy Connor, Michael Connor, Stan Day, Pam Hughes, Jane Villebrun, Beverly Steel, Muriel Deegan, and Ray Villebrun. The authors respectfully acknowledge the commitment and participation of project team members in addition to their thoughtful review of this manuscript.

\section{References}

1. Barnes PM, Adams PF, Powell-Griner E. Health characteristics of the American Indian or Alaska Native adult population: United States, 2004-2008 National health statistics reports; no 20. Hyattsville, MD: National Center for Health Statistics. 2010.

2. Marmot M, Wilkinson R. Social determinants of health. 2nd ed. New York: Oxford University Press; 2005.

3. King M, Smith A, Gracey M. Indigenous health part 2: The underlying causes of the health gap. Lancet 2009;374:76-85.

4. Highlights: 2013 National Healthcare Quality \& Disparities Reports. Rockville: Agency for Healthcare Research and Quality.

5. Sue DW. 2010 Microaggressions in everyday life: Race, gender, and sexual orientation. Hoboken: John Wiley \& Sons.

6. Cohen S, Williamson GM. Stress and infectious disease in humans. Psychol Bull 1991;109:5.

7. Krantz DS, Whittaker KS, Sheps DS. 2011 Psychosocial risk factors for coronary heart disease: Pathophysiologic mechanisms. In: Allan R, ed. Heart and mind: Evolution of cardiac psychology. Washington DC, APA Press.

8. McEwen BS, Stellar E. Stress and the individual: Mechanisms leading to disease. Arch Intern Med 1993;153:2093.

9. McEwen BS. Stress, adaptation, and disease. Allostasis and allostatic load. Ann N Y Acad Sci 1998;840: 33-44.

10. Motzer SA, Hertig V. Stress, stress response, and health. Nurs Clin North Am 2004;39:1-17.

11. Selye H. Stress in health and disease. Boston: Butterworths; 1976.

12. Selye H. The stress concept. Can Med Assoc J 1976; 115:718. 
13. Wheaton B. 1994 Stress and mental health: Contemporary issues and prospects for the future. Avison WR and Gotlib IH, eds. The Plenum series on stress and coping. New York: Plenum Press; 77-114.

14. Williams DR, Mohammed SA. Discrimination and racial disparities in health: evidence and needed research. J Behav Med 2009;32:20-47.

15. Hausmann LR, Jeong K, Bost JE, Ibrahim SA. Perceived discrimination in health care and health status in a racially diverse sample. Med Care 2008;46:905914.

16. Paradies Y. A systematic review of empirical research on self-reported racism and health. Int J Epidemiol 2006;35:888-901.

17. Williams DR, Neighbors HW, Jackson JS. Racial/ ethnic discrimination and health: findings from community studies. Am J Public Health 2003;93:200208.

18. World Health Organization. 2003 Social determinants of health: the solid facts, 2 nd ed. Wilkinson R, Marmot M, eds. Copenhagen: WHO Regional Office for Europe.

19. Paradies Y, Truong M, Priest N. A systematic review of the extent and measurement of healthcare provider racism. J Gen Intern Med 2014;364-387.

20. Lee C, Ayers SL, Kronenfeld JJ. The association between perceived provider discrimination, healthcare utilization and health status in racial and ethnic minorities. Ethn Dis 2009;19:330-337.

21. Pasco EA, Richman LS. Perceived discrimination and health: a meta-analytic review. Psychol Bull 2009;135:531-534.

22. Hobson WD. 2001 Racial discrimination in health care interview project-A special report. Seattle: Public Health-Seattle \& King County.

23. Centers for Disease Control. CDC Health Disparities and Inequalities Report-United States, 2011. http://www. cdc.gov/mmwr/pdf/other/su6203.pdf. Updated November 22, 2013. Accessed February 17, 2014.

24. Minnesota Department of Health. Advancing health equity in Minnesota: Report to the legislature. http:// www.health.state.mn.us/divs/chs/healthequity/ahe_leg_ report_020414.pdf. Updated February 1, 2014. Accessed February 17, 2014.

25. Blair IV, Steiner JF, Fairclough DL, et al. Clinicians' implicit ethnic/racial bias and perceptions of care among black and Latino patients. Ann Fam Med 2013;11:43-52.

26. Subban JE, Terwoord NA, Schuster RJ. With or without intent: how racial disparities prevent effective implementation of care. J Nutr Health Aging 2008;12:770-775.

27. Sue DW, Capodilupo CM, Torino GC, Bucceri JM, Holder AM, Nadal KL, Esquilin M. Racial micro- aggressions in everyday life: implications for clinical practice. Am Psychol 2007;62:271-286.

28. Constantine M. Racial microaggressions against African American clients in cross-racial counseling relationships. J Couns Psychol 2007;54:1-16.

29. Schiller JS, Lucas JW, Ward BW, Peregoy JA. Summary health statistics for U.S. adults: National Health Interview Survey, 2010. Vital Health Stat 10 2012;252:1-207.

30. Harjo TC, Perez A, Lopez V, Wong ND. Prevalence of diabetes and cardiovascular risk factors among California Native American adults compared to other ethnicities: the 2005 California Health Interview Survey. Metab Syndr Relat Disord 2011;9: 49-54.

31. American Diabetes Association. Standards of medical care in diabetes-2014. Diabetes Care. 2014; 37(Supplement 1):S14-S80.

32. Piette JD, Bibbins-Domingo $\mathrm{K}$, Schillinger $\mathrm{D}$. Health care discrimination, processes of care, and diabetes patients' health status. Patient Educ Couns 2006;60:41-48.

33. Peek ME, Wagner J, Tang H, Baker DC, Chin MH. Self-reported racial/ethnic discrimination in health care and diabetes outcomes. Med Care 2011;49:618625.

34. Treuer A. 2010 Ojibwe in Minnesota. St. Paul: Minnesota Historical Society Press.

35. Spitzer RL, Kroenke K. Validation and utility of a self-report version of PRIME-MD: the PHQ primary care study. Primary Care Evaluation of Mental Disorders. Patient Health Questionnaire. JAMA 1999;282:1737-1744.

36. Paradies YC, Cunningham J. The DRUID study: Racism and self-assessed health status in an indigenous population. BMC public health 2012;12:131143.

37. Saha S, Beach MC, Cooper LA. Patient centeredness, cultural competence and healthcare quality. J Natl Med Assoc 2008;100:1275-1285.

38. Epner DE, Baile WF. Patient-centered care: The key to cultural competence. Ann Oncol 2012;23:33-42.

39. Kleinman A, Benson P. Anthropology in the clinic: The problem of cultural competency and how to fix it. PLoS Med 2006;3:e294.

40. Tervalon M, Murray-García J. Cultural humility versus cultural competence: A critical distinction in defining physician training outcomes in multicultural education. J Health Care Poor Underserved 1998;9:117-125.

41. Polaschek NR. Cultural safety: A new concept in nursing people of different ethnicities. J Adv Nurs 1998;27:452-457.

42. Nguyen HT. Patient centred care - cultural safety in indigenous health. Aust Fam Physician 2008;37:990-994. 